\title{
Thermal Behavior with Mechanical Property of Fluorinated Silane Functionalized Superhydrophobic Pullulan/Poly(vinyl alcohol) Blends by Electrospinning Method
}

\author{
Mohammad Rezaul Karim ${ }^{1}$ and Md. Shahidul Islam² \\ ${ }^{1}$ Center of Excellence for Research in Engineering Materials, College of Engineering, King Saud University, Riyadh 11421, Saudi Arabia \\ ${ }^{2}$ Department of Applied Chemistry and Chemical Engineering, University of Dhaka, Dhaka 1000, Bangladesh
}

Correspondence should be addressed to Mohammad Rezaul Karim, mkarim@ksu.edu.sa

Received 14 June 2011; Accepted 19 August 2011

Academic Editor: Gaurav Mago

Copyright ( 2011 M. R. Karim and Md. S. Islam. This is an open access article distributed under the Creative Commons Attribution License, which permits unrestricted use, distribution, and reproduction in any medium, provided the original work is properly cited.

\begin{abstract}
Fluorinated silane functionalized superhydrophobic pullulan/poly(vinyl alcohol) (PULL/PVA) blend membrane with water contact angle larger than $150^{\circ}$ has been prepared by the electrospinning method. The morphology, thermal stability, and mechanical property of the membranes are characterized using scanning electron microscopy (SEM), thermogravimetric analysis (TGA), and ZWICK materials testing machine, respectively. Interactions between PULL and PVA and PULL/PVA blends with perfluorooctyltriethoxysilane (PFOTES) of the membranes are analyzed using differential scanning calorimetry (DSC) and Fourier transform infrared (FTIR). Contact angles and water drops on the surface of the membrane are measured by video microscopy. The study shows that the addition of minor quantity of PVA with PULL results in improvement in thermal stability and mechanical property (tensile strength) of the PULL membranes.
\end{abstract}

\section{Introduction}

The wettability of a solid surface is an interesting property of a material and is described as the contact angle between a liquid and a solid surface. When the contact angle between water and a solid surface is larger than $150^{\circ}$, this solid surface is called a superhydrophobic surface [1]. Superhydrophobic surfaces are widely found in nature. For example, the surface of a lotus leaf is observed to be an array of nanoscale buds [2]. Water drops on the surface of the leaf tend to slide down, rendering its self-cleaning property. The surfaces which mimic "lotus effect" have triggered extensive interests for their potential applications involving water repellency, selfcleaning, and antifouling properties [3-6]. Generally, the hydrophobicity of surfaces depends on both their chemical composition and surface geometrical structure [7]. In terms of chemical composition, hydrophobicity can only be increased by introducing a component with low surface energy such as fluorinated methyl groups. However, this method to increase hydrophobicity is limited.
The maximum contact angle that can be reached by coating fluorinated methyl groups onto a flat solid surface is only $120^{\circ}$, which can be hardly called superhydrophobic [8]. Therefore, a hierarchical structure is introduced into the solid surface to achieve superhydrophobicity. A number of methods have been used to make a hierarchical superhydrophobic surface including phase separation [9], electrochemical deposition [10], chemical vapor deposition [11], crystallization control [12], photolithography [13], assembly [14], sol-gel methods [15], solution-immersion methods [16], and array of nanotubes/nanofibers [17, 18].

Electrospinning is a simple but versatile method to produce continuous fibers with diameters ranging from nanometer to submicron scale. Superhydrophobic surfaces can be obtained through this process by controlling the surface roughness under appropriate conditions $[19,20]$. Superhydrophobic polystyrene nanofibers were electrospun by either using various solvents [8] or adding room temperature ionic liquid [21]. Cellulose triacetate fibrous mat [22] and poly(3-hydroxybutyrate-co-3-hydroxyvalerate) (PHBV) 
fibrous surfaces [23] are fabricated using electrospun fibers followed with plasma treatment. Electrospun nanofibers from the blending solution of fully hydrolyzed medium molecular weight poly(vinyl alcohol) and high-molecularweight poly(vinyl alcohol) with montmorillonite were fabricated [24].

Pullulan is a natural polymer with excellent biocompatibility. The use of natural polymer has created tremendous interest recently, for example, as proteins in biotechnological materials and biomedical applications [25]. However, only few reports are available in the literature regarding superhydrophobic PULL membrane prepared by electrospinning. Pullulan's solubility can be controlled or provided with reactive groups by chemical derivatization. Due to its excellent properties, pullulan is used as a low-calorie ingredient in foods, gelling agent, coating and packaging material for food and drugs, binder for fertilizers, and as an oxidationprevention agent for tablets. Other applications include contact lenses manufacturing, biodegradable foil, plywood, water solubility enhancer, and for enhancing oil recovery [26-29].

Poly(vinyl alcohol) (PVA) is a semicrystalline hydrophilic polymer with good chemical and thermal stability. It is a highly biocompatible and nontoxic polymer and it can be processed easily; it also has high water permeability. PVA can form physical gels in various types of solvents which lead to the use of PVA in a wide range of applications in medical, cosmetic, food, pharmaceutical, and packaging industries [30-36].

Polymer blending constitutes a very useful method for the improvement or modification of the physicochemical properties of polymeric materials. An important property of a polymer blend is the miscibility of its components because it affects the mechanical properties, the morphology, and the permeability and degradation. Polymer blends are physical mixtures of structurally different polymers or copolymers that interact with secondary forces with no covalent bonding [37], such as hydrogen bonding, dipole-dipole forces, and charge-transfer complexes for homopolymer mixtures [3840].

In our previous report, we prepared fluorinated silane functionalized pullulan superhydrophobic membrane using electrospinning technique [41]. In this study, fluorinated silane functionalized superhydrophobic PULL/PVA blend membranes are made to enhance the thermal stability and mechanical property (tensile strength) of PULL membranes by applying the same technique.

\section{Experimental}

2.1. Materials. Pullulan is a food grade preparation (PF-20 grade) from Hayashibara Biochemical Laboratories Inc. (Okayama, Japan), PVA with $P_{n}=1,700$ (fully hydrolyzed, degree of saponification $=99.9 \%$ ) was obtained from DC Chemical, Seoul, Republic of Korea and perfluorooctyltriethoxysilane (PFOTES) is purchased from Aldrich Chemical Company. Doubly distilled water is used as a solvent to prepare all solutions.
2.2. Preparation of PULL/PVA/PFOTES Blend Solutions. The PULL/PVA solutions (total polymer concentrations are 9 and 12 wt.\%) with $80 / 20$ mass ratio were prepared in doubly distilled water at $80^{\circ} \mathrm{C}$ temperature under magnetic stirring for 2-3 h. The PULL/PVA/PFOTES blend solutions were prepared by mixing of the PULL/PVA solutions with $1 \mathrm{wt} . \%$ of PFOTES with gently stirred for further $24 \mathrm{~h}$. The formed solutions were then used for the preparation of membranes using electrospinning technique.

2.3. Membrane Preparation by Electrospinning. During electrospinning, each solution was continuously supplied using a syringe pump with a speed of $0.04 \mathrm{~mL} / \mathrm{h}$ through a $25 \mathrm{G}$ needle producing a Taylor cone. A high power voltage $(15 \mathrm{kV})$ was supplied to the solution with a tip-to-collector distance of $15 \mathrm{~cm}$. Membranes were collected on electrically grounded aluminum foil placed at a vertical distance to the needle tip. Trace amount of PFOTES does not affect the electrospinnability of PULL/PVA blend solution.

2.4. Characterization of Membranes. The water contact angles of the membranes were measured using video microscopy. Using a microsyringe, $5 \mu \mathrm{L}$ deionized water was dropped perpendicularly to each surface of the membranes placed on a horizontal glass sheet. Then, the images of water drops on the surface of the membranes were observed using Scalar Video Loupe (VL-11s) and analyzed using the Sigma TV II program. Membranes were also characterized with FTIR (IFS 120HR, Bruker) and DSC (model Q-10) from TA instruments, USA. The morphology, thermal stability, and mechanical property (tensile strength) of membranes were observed with a field-emission scanning electron microscope (JEOL, model JSM-6380) after gold coating, TGA technique (model Q-50; TA Instruments, USA), and ZWICK Z005 (ZWICK materials testing machine, Germany), respectively.

\section{Results and Discussion}

3.1. DSC Data of Membranes. Figure 1 illustrates the DSC thermograms of pure PULL, PVA, and electrospun PULL/PVA blend membrane with $80 / 20$ mass ratio at a total polymer concentration of $9 \mathrm{wt} . \%$. A relatively large and sharp endothermic peak is observed at about $224^{\circ} \mathrm{C}$ (Figure 1(a)) and is assigned to the melting temperature of pure PVA, which has a number-average degree of polymerization of 1700 , which agrees very well with reported data [42]. This peak is shifted to $206.50^{\circ} \mathrm{C}$ with the addition of $80 \mathrm{wt} . \%$ PULL (Figure 1(b)), and this shifts the melting temperature to lower value; this occurred because of the addition of PULL whose melting temperature changes from 95 to $84^{\circ} \mathrm{C}$ (Figure 1(b)). This is because the majority of the chains are in a noncrystalline state due to the rapid solidification process of stretched chains during electrospinning. Pure PULL shows a large thermogram peak of melting transition $\left(T_{m}\right)$ at $95^{\circ} \mathrm{C}$ (Figure $1(\mathrm{c})$ ).

The interactions between PULL/PVA blending and PFOTES of membranes are investigated by DSC. Figure 2 shows the DSC thermogram of PULL/PVA/PFOTES blend membrane with 1 wt. $\%$ of PFOTES contents and 80/20 mass 


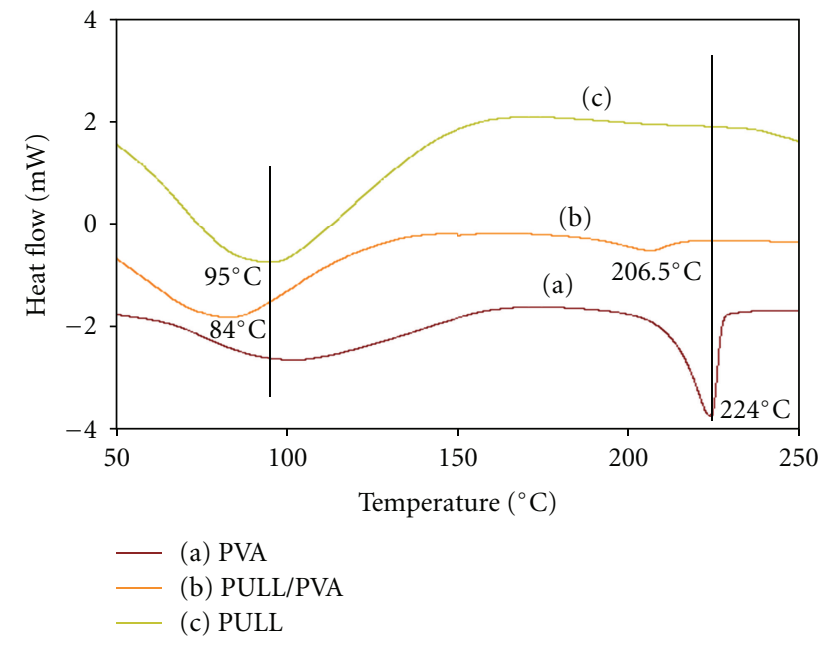

Figure 1: DSC data of (a) PVA, (b) PULL/PVA blend membrane using electrospinning method (Applied voltage $=15 \mathrm{kV}, \mathrm{TCD}=$ $15 \mathrm{~cm}$, Blend ratio (PULL/PVA) $=80 / 20$, and Total polymer concentration $=9 \mathrm{wt} . \%)$, and $(\mathrm{c})$ PULL.

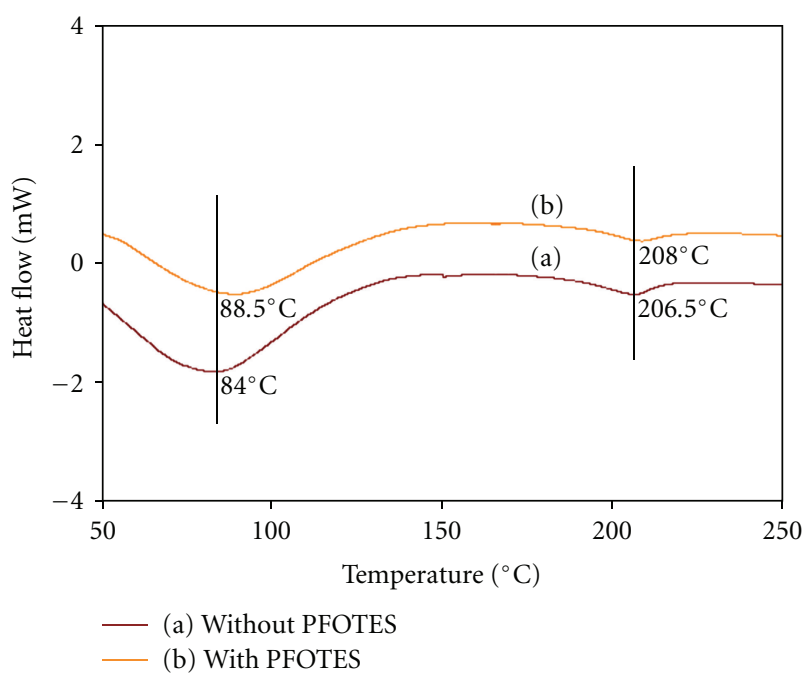

Figure 2: DSC data of PULL/PVA blend membranes (a) without PFOTES, and (b) with PFOTES using electrospinning method (Applied voltage $=15 \mathrm{kV}, \mathrm{TCD}=15 \mathrm{~cm}$, Blend ratio $(\mathrm{PULL} / \mathrm{PVA})=$ $80 / 20$, and Total polymer concentration $=9 \mathrm{wt} . \%)$.

ratio of those two polymers at a total polymer concentration of 9 wt.\%. Without PFOTES, PULL/PVA membrane shows two thermogram peaks of melting transitions $\left(T_{m}\right)$ at $84^{\circ} \mathrm{C}$, and $206.50^{\circ} \mathrm{C}$ (Figure 2(a)). These peaks are shifted to $88.5^{\circ} \mathrm{C}$ and $208^{\circ} \mathrm{C}$ with the addition of $1 \mathrm{wt} . \%$ PFOTES (Figure 2(b)). The DSC thermograms for the membranes show clearly the melting transitions of the PULL/PVA blend membrane, in which there are significant effects of the PFOTES content. The dramatic changes of $T_{m}$ of the composite membranes can be attributed by the introduction of $\mathrm{CF}_{3}$ groups into heteroatom (O atom) containing hydrophobic carbon ring of PULL and hydrophobic carbon chain of PVA.

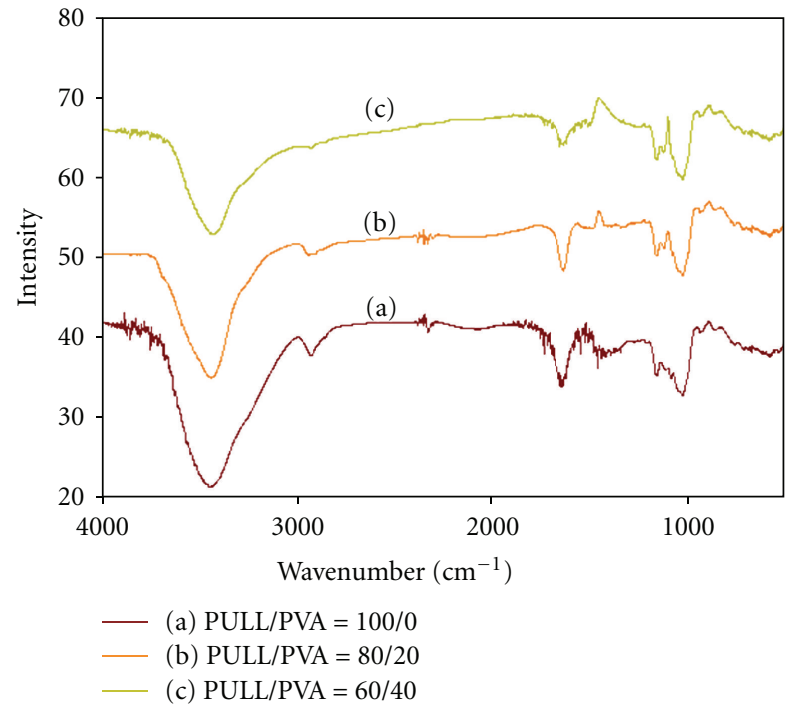

FIgURE 3: FTIR data of PULL/PVA blend membrane with various weight ratios of (a) 100/0, (b) 80/20, and (c) 60/40 using electrospinning method (Applied voltage $=15 \mathrm{kV}, \mathrm{TCD}=15 \mathrm{~cm}$, and Total polymer concentration $=9 \mathrm{wt} . \%)$.

3.2. FTIR Data of Membranes. FTIR spectra give information about the structure of blend membranes studied. In Figure 3, examples of spectra of pure PULL and PULL/PVA blend membranes at $500-4000 \mathrm{~cm}^{-1}$ range are shown. Pure PULL membrane exhibits identical bands as shown in Figure 3(a). Strong absorption in $850 \mathrm{~cm}^{-1}$ is characteristic of the a-glucopyranoside units. Absorption in $755 \mathrm{~cm}^{-1}$ indicates the presence of $\alpha-(1,4)$ glucosidic bonds, and spectra in $932 \mathrm{~cm}^{-1}$ proves the presence of $\alpha-(1,6)$ glucosidic bonds. Besides, in the areas for reference and evaluated samples the frequencies are analogous [43]. Bands at $2850-3000 \mathrm{~cm}^{-1}$ are due to stretching vibrations of $\mathrm{CH}$ and $\mathrm{CH}_{2}$ groups and bands attribute to $\mathrm{CH} / \mathrm{CH}_{2}$ deformation vibrations are present at $1300-1500 \mathrm{~cm}^{-1}$ range. Also very intensive, broad hydroxyl band occurs at $3000-3600 \mathrm{~cm}^{-1}$ and accompanying $\mathrm{C}-\mathrm{O}$ stretching exists at $1000-1260 \mathrm{~cm}^{-1}$. With the addition of PVA, some absorption peaks of PULL become lower in intensity, whereas some absorption peaks at 1096 and $1447 \mathrm{~cm}^{-1}$ appear and the intensity of these peaks increases with augmenting the concentration of PVA (Figures 3 (b) and $3(c))$. This suggests that hydrogen bonds between hydroxyl groups in PULL and hydroxyl groups in PVA could possibly play a role in the shift of the peaks. Thus, the FTIR spectroscopy supports the interactions between PULL and PVA, which are suggested above. Moreover, the absorption peaks which appeared at $1145 \mathrm{~cm}^{-1}, 1235 \mathrm{~cm}^{-1}$, and $1430 \mathrm{~cm}^{-1}$ are attributed to the vibrations of $\mathrm{CF}_{2}$ and $\mathrm{CF}_{3}$ groups in PFOTES and the absorption peaks at $700-800 \mathrm{~cm}^{-1}$ are due to the vibration of Si-O groups in the silanes (Figure 4(b)). Thus, the FTIR spectroscopy supplies also evidences of possible interactions between PULL/PVA blend and PFOTES, which are suggested by DSC.

3.3. TGA Data of Membranes. Thermal stability of PULL/PVA membranes is measured using TGA in nitrogen 


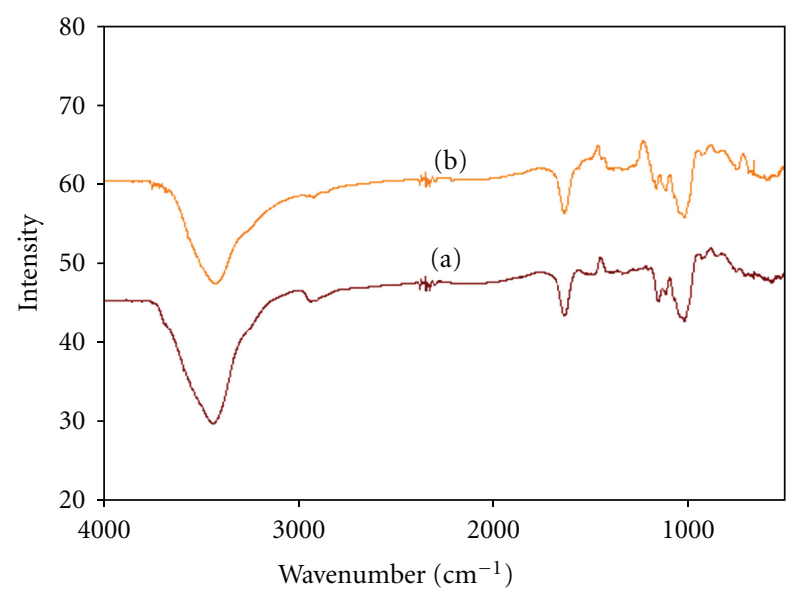

- (a) Without PFOTES

- (b) With PFOTES

FIgUre 4: FTIR data of PULL/PVA blend membranes (a) without PFOTES, and (b) with PFOTES using electrospinning method (applied voltage $=15 \mathrm{kV}, \mathrm{TCD}=15 \mathrm{~cm}$, blend ratio $(\mathrm{PULL} / \mathrm{PVA})=$ $80 / 20$, and total polymer concentration $=9 \mathrm{wt} . \%)$.

TABLE 1: Tensile strength of PULL/PVA blend membranes as a function of PVA contents using electrospinning method (applied voltage $=15 \mathrm{kV}, \mathrm{TCD}=15 \mathrm{~cm}$, and total polymer concentration $=9 \mathrm{wt} . \%)$.

\begin{tabular}{lc}
\hline PVA content (wt.\%) & Tensile strength (MPa) \\
\hline 0 & $5.12 \pm 0.25$ \\
5 & $5.27 \pm 0.25$ \\
10 & $5.42 \pm 0.25$ \\
15 & $5.54 \pm 0.25$ \\
20 & $5.65 \pm 0.25$ \\
\hline
\end{tabular}

atmosphere. Figure 5 shows TGA thermograms of different decomposition temperature with PULL/PVA mass ratios of $100 / 0$, and $80 / 20$. The below curve of the TGA data (Figure 5(a)) represents the pure PULL membrane and the upper curve (Figure 5(b)) is for 80/20 blend ratio of PULL/ PVA. Clearly, it can be seen that higher thermal stability of the membranes could be with the addition of PVA in the PULL/PVA blend system.

3.4. Tensile Strength. Some of the fascination with the behavior of polymers comes from the large changes in the physical properties and the wide range of mechanical behaviours [44]. The tensile strength of the PULL/PVA blend membranes increases with augmenting the weight percentage of PVA, as shown in Table 1.

3.5. Water Contact Angles of Membranes. Membranes prepared by electrospinning method have much higher contact angle because of the high surface area of the formed fibers that ranges from nanometer to submicron scale. As shown in Figure 6(a), nanofibers electrospun using total polymer concentration $9 \mathrm{wt} . \%$ contain a large number of beads in nanometer size $(500-1000 \mathrm{~nm})$, whereas less number of beads containing nanofibers can be electrospun using total

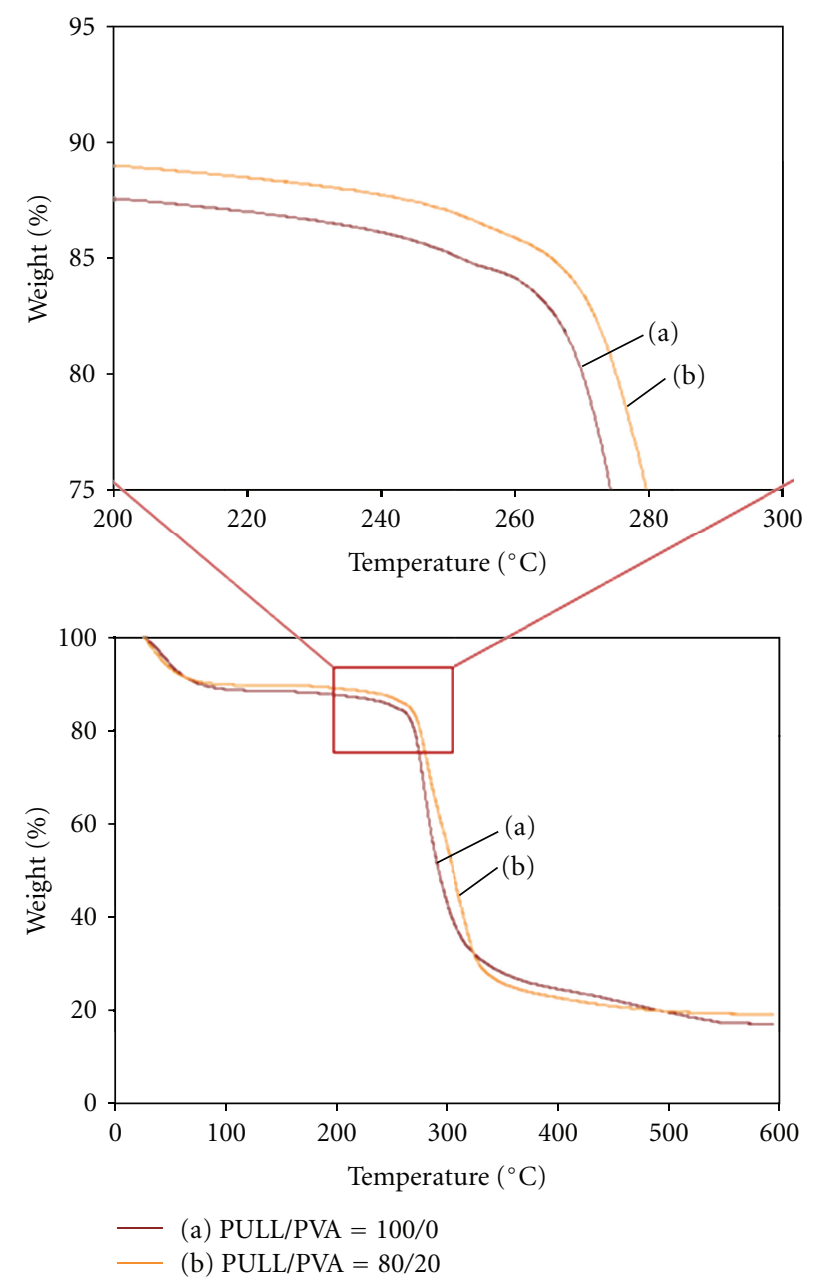

FIgURe 5: TGA data of PULL/PVA blend membrane with weight ratios of (a) 100/0 and (b) 80/20 using electrospinning method (applied voltage $=15 \mathrm{kV}, \mathrm{TCD}=15 \mathrm{~cm}$, and total polymer concentration $=9 \mathrm{wt} . \%)$.

polymer concentration of $12 \mathrm{wt} . \%$, and $9 \mathrm{wt.} \%$ and $12 \mathrm{wt.} \%$ of total polymer concentrations coupled with PFOTES applying the same parameters as shown in Figures 6(b), 6(c), and $6(\mathrm{~d})$, respectively. The obtained nanofibers are ranged from 200 to $800 \mathrm{~nm}$. The reason for different bead contents in each concentration is that the Rayleigh forces, which assist in bead formation, are able to overcome the viscous forces to enable the formation of beads [45]. Moreover, strong interaction between PULL/PVA blends and PFOTES is attributed to the formation of less number of beads in the fibers. The interaction between PULL/PVA blends and PFOTES can be put forward as a cause to two factors.

First, the introduction of hydrophobic $\mathrm{CF}_{3}$ groups on the heteroatom $(\mathrm{O}$ atom $)$ containing hydrophobic carbon ring of PULL and hydrophobic carbon chain of PVA and the second factor is the interaction obtained from the formation of hydrogen bonding between polar hydrogen of - $\mathrm{OH}$ group of PULL and PVA with O of PFOTES. Although contact angles of up to $147^{\circ}$ (Figure 6(a)) and $142^{\circ}$ (Figure 6(b)) can be reached by directly electrospinning of $9 \mathrm{wt} . \%$ and $12 \mathrm{wt} . \%$ 


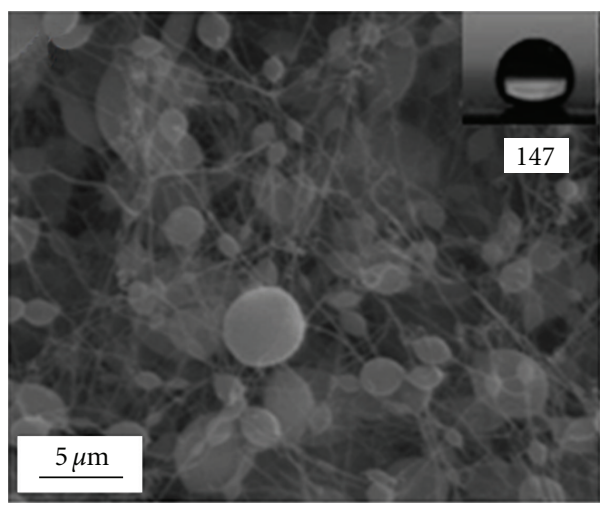

(a)

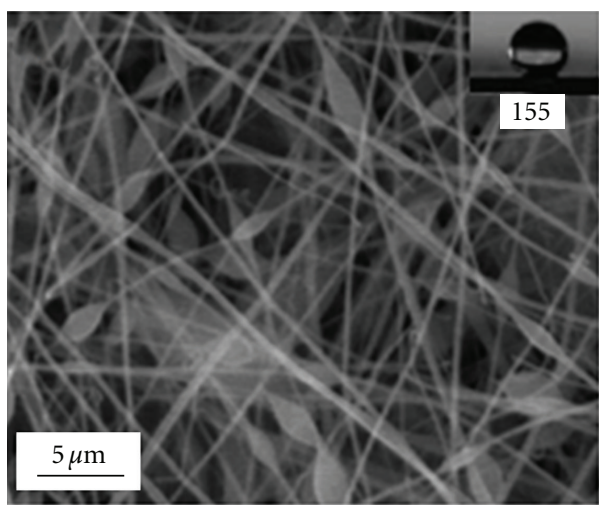

(c)

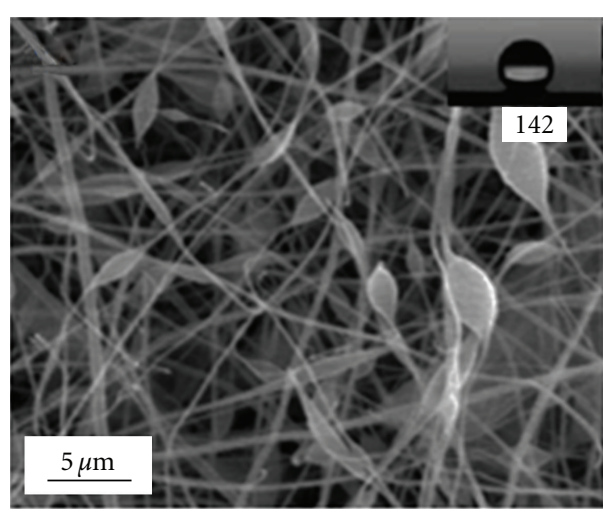

(b)

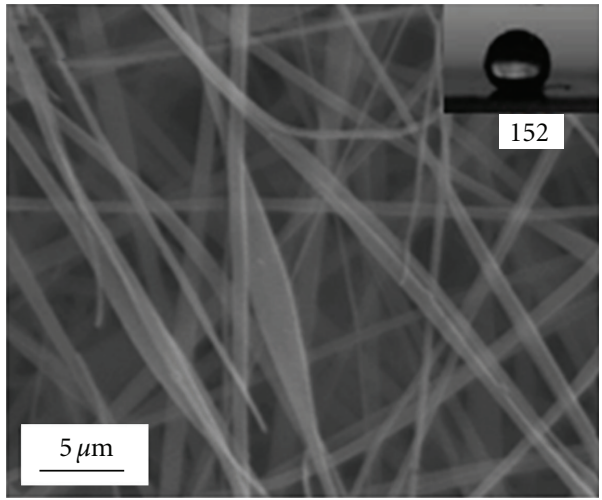

(d)

Figure 6: SEM images of membranes prepared from PULL/PVA blend solutions of total polymer concentrations of (a) 9 wt.\%, (b) 12 wt.\%, (c) 9 wt.\% with PFOTES, (d) $12 \mathrm{wt} . \%$ with PFOTES using electrospinning method (applied voltage $=15 \mathrm{kV}$, TCD $=15 \mathrm{~cm}$, blend ratio $(\mathrm{PULL} / \mathrm{PVA})=80 / 20)$.

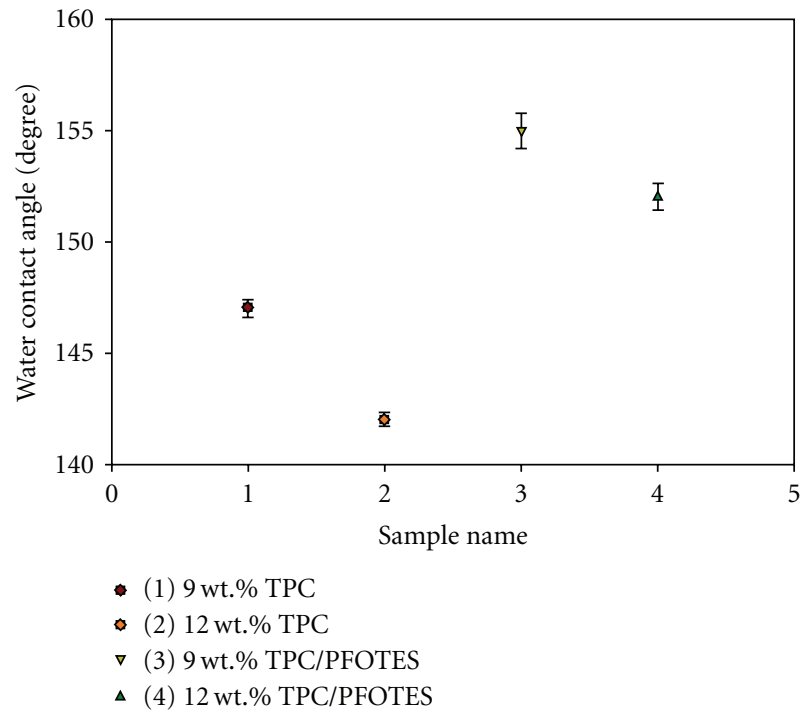

FIGURE 7: Variation of water contact angle with different compositions of PULL/PVA blend polymers of (1) $9 \mathrm{wt} . \%$ total polymer concentration (TPC), (2) $12 \mathrm{wt} . \%$ total polymer concentration (TPC), (3) 9 wt.\% TPC with PFOTES, and (4) 12 wt.\% TPC with PFOTES (blend ratio, PULL/PVA $=80 / 20$ ).
TABLE 2: Water contact angles of the prepared membranes.

\begin{tabular}{lcc}
\hline Samples & $\begin{array}{c}\text { PULL/PVA blend ratio } \\
\text { (by wt.\%) }\end{array}$ & $\begin{array}{c}\text { Water contact } \\
\text { angles }\end{array}$ \\
\hline 9 wt.\% TPC & & $147 \pm 0.25$ \\
12 wt.\% TPC & $80 / 20$ & $142 \pm 0.15$ \\
9 wt.\% TPC/PFOTES & & $155 \pm 1.0$ \\
12 wt.\% TPC/PFOTES & & $152 \pm 0.5$ \\
\hline
\end{tabular}

TPC: total polymer concentration.

of total polymer concentration solutions, respectively, the membranes can not still be considered as superhydrophobic membranes. Therefore, $9 \mathrm{wt} . \%$ and $12 \mathrm{wt} . \%$ of total polymer concentration solutions coupled with PFOTES are used to successfully prepare superhydrophobic membranes with high-contact angles of $155^{\circ}$ (Figure 6(c)) and $152^{\circ}$ (Figure 6(d)), respectively. Water contact angles of all samples taken in this experiment are shown in Figure 7 (data are given in Table 2). Higher contact angle of $9 \mathrm{wt} . \%$ of total polymer concentration than that of $12 \mathrm{wt} . \%$ total polymer concentration can be explained on the basis of surface roughness like lotus leaf [2] due to the more bead formation in case of $9 \mathrm{wt} . \%$. 


\section{Conclusions}

Superhydrophobic PULL/PVA membranes are prepared by electrospinning from fluorinated silane functionalized PULL/PVA blends. It is observed that both of $9 \mathrm{wt} . \%$ and $12 \mathrm{wt} . \%$ of total polymer concentration membranes can only reach contact angles lower than $150^{\circ}$ by electrospinning of PULL/PVA blends without using PFOTES. Superhydrophobic membranes with contact angles of up to $155^{\circ}$ and $152^{\circ}$ can be achieved by electrospinning of $9 \mathrm{wt} . \%$ and $12 \mathrm{wt} . \%$ of total polymer concentration solutions coupled with fluorinated silane, respectively. Moreover, thermal stability and mechanical property of the PULL membranes has been enhanced with the introduction of PVA.

\section{Acknowledgment}

This project was supported by King Saud University, Deanship of Scientific Research, College of Engineering Research Center.

\section{References}

[1] X. Feng and L. Jiang, "Design and creation of superwetting/ antiwetting surfaces," Advanced Materials, vol. 18, no. 23, pp. 3063-3078, 2006.

[2] W. Barthlott and C. Neinhuis, "Purity of the sacred lotus, or escape from contamination in biological surfaces," Planta, vol. 202, no. 1, pp. 1-8, 1997.

[3] L. Feng, S. Li, Y. Li et al., "Super-hydrophobic surfaces: from natural to artificial," Advanced Materials, vol. 14, no. 24, pp. 1857-1860, 2002.

[4] A. Lafuma and D. Quere, "Superhydrophobic states," Nature Materials, vol. 2, no. 7, pp. 457-460, 2003.

[5] R. Blossey, "Self-cleaning surfaces-Virtual realities," Nature Materials, vol. 2, no. 5, pp. 301-306, 2003.

[6] H. Y. Erbil, A. L. Demirel, Y. Avci, and O. Mert, "Transformation of a simple plastic into a superhydrophobic surface," Science, vol. 299, no. 5611, pp. 1377-1380, 2003.

[7] D. Quéré, "Rough ideas on wetting," Physica A, vol. 313, no. 1-2, pp. 32-46, 2002.

[8] M. Kang, R. Jung, H. S. Kim, and H. J. Jin, "Preparation of superhydrophobic polystyrene membranes by electrospinning," Colloids and Surfaces A, vol. 313-314, pp. 411-414, 2008.

[9] J. T. Han, X. Xu, and K. Cho, "Diverse access to artificial superhydrophobic surfaces using block copolymers," Langmuir, vol. 21, no. 15, pp. 6662-6665, 2005.

[10] M. Li, J. Zhai, H. Liu, Y. Song, L. Jiang, and D. Zhu, "Electrochemical deposition of conductive superhydrophobic zinc oxide thin films," Journal of Physical Chemistry B, vol. 107, no. 37, pp. 9954-9957, 2003.

[11] H. Liu, L. Feng, J. Zhai, L. Jiang, and D. Zhu, "Reversible wettability of a chemical vapor deposition prepared $\mathrm{ZnO}$ film between superhydrophobicity and superhydrophilicity," Langmuir, vol. 20, no. 14, pp. 5659-5661, 2004.

[12] T. Onda, S. Shibuichi, N. Satoh, and K. Tsujii, "Super-waterrepellent fractal surfaces," Langmuir, vol. 12, no. 9, p. 2125, 1996.

[13] T. J. McCarthy and D. Oner, "Ultrahydrophobic surfaces. Effects of topography length scales on wettability," Langmuir, vol. 16, no. 20, pp. 7777-7782, 2000.
[14] F. Shi, Z. Wang, and X. Zhang, "Combining a layer-by-layer assembling technique with electrochemical deposition of gold aggregates to mimic the legs of water striders," Advanced Materials, vol. 17, no. 8, pp. 1005-1009, 2005.

[15] K. Tadanaga, J. Morinaga, A. Matsuda, and T. Minami, "Superhydrophobic-Superhydrophilic micropatterning on flowerlike alumina coating film by the sol-Gel method," Chemistry of Materials, vol. 12, no. 3, pp. 590-592, 2000.

[16] S. Wang, L. Feng, and L. Jiang, "One-step solution-immersion process for the fabrication of stable bionic superhydrophobic surfaces," Advanced Materials, vol. 18, no. 6, pp. 767-770, 2006.

[17] T. Sun, G. Wang, H. Liu, L. Feng, L. Jiang, and D. Zhu, "Control over the wettability of an aligned carbon nanotube film," Journal of the American Chemical Society, vol. 125, no. 49, pp. 14996-14997, 2003.

[18] L. Feng, Y. Song, J. Zhai et al., "Creation of a superhydrophobic surface from an amphiphilic polymer," Angewandte Chemie, vol. 42, no. 7, pp. 800-802, 2003.

[19] L. Jiang, Y. Zhao, and J. Zhai, "A lotus-leaf-like superhydrophobic surface: a porous microsphere/nanofiber composite film prepared by electrohydrodynamics," Angewandte Chemie, vol. 43, no. 33, pp. 4338-4341, 2004.

[20] M. Ma, R. M. Hill, J. L. Lowery, S. V. Fridrikh, and G. C. Rutledge, "Electrospun poly(styrene-block-dimethylsiloxane) block copolymer fibers exhibiting superhydrophobicity," Langmuir, vol. 21, no. 12, pp. 5549-5554, 2005.

[21] X. Lu, J. Zhou, Y. Zhao, Y. Qiu, and J. Li, "Room temperature ionic liquid based polystyrene nanofibers with superhydrophobicity and conductivity produced by electrospinning," Chemistry of Materials, vol. 20, no. 10, pp. 3420-3424, 2008.

[22] Y. I. Yoon, H. S. Moon, W. S. Lyoo, T. S. Lee, and W. H. Park, "Superhydrophobicity of cellulose triacetate fibrous mats produced by electrospinning and plasma treatment," Carbohydrate Polymers, vol. 75, no. 2, pp. 246-250, 2009.

[23] Y. I. Yoon, H. S. Moon, W. S. Lyoo, T. S. Lee, and W. H. Park, "Superhydrophobicity of PHBV fibrous surface with bead-onstring structure," Journal of Colloid and Interface Science, vol. 320, no. 1, pp. 91-95, 2008.

[24] H. M. Ji, H. W. Lee, M. R. Karim et al., "Electrospinning and characterization of medium-molecular-weight poly(vinyl alcohol)/high-molecular-weight poly(vinyl alcohol)/ montmorillonite nanofibers," Colloid and Polymer Science, vol. 287, no. 7, pp. 751-758, 2009.

[25] H. J. Jin, J. Chen, V. Karageorgiou, G. H. Altman, and D. L. Kaplan, "Human bone marrow stromal cell responses on electrospun silk fibroin mats," Biomaterials, vol. 25, no. 6, pp. 1039-1047, 2004.

[26] C. J. Israilides, A. Smith, J. E. Harthill, C. Barnett, G. Bambalov, and B. Scanlon, "Pullulan content of the ethanol precipitate from fermented agro- industrial wastes," Applied Microbiology and Biotechnology, vol. 49, no. 5, pp. 613-617, 1998.

[27] T. D. Leathers, "Biotechnological production and applications of pullulan," Applied Microbiology and Biotechnology, vol. 62, no. 5-6, pp. 468-473, 2003.

[28] R. Schuster, E. Wenzig, and A. Mersmann, "Production of the fungal exopolysaccharide pullulan by batch-wise and continuous fermentation," Applied Microbiology and Biotechnology, vol. 39, no. 2, pp. 155-158, 1993.

[29] M. R. Karim, H. W. Lee, R. Kim et al., "Preparation and characterization of electrospun pullulan/montmorillonite nanofiber mats in aqueous solution," Carbohydrate Polymers, vol. 78, no. 2, pp. 336-342, 2009. 
[30] G. Ren, X. Xu, Q. Liu et al., "Electrospun poly(vinyl alcohol)/glucose oxidase biocomposite membranes for biosensor applications," Reactive and Functional Polymers, vol. 66, no. 12, pp. 1559-1564, 2006.

[31] C. Shao, H.-Y. Kim, J. Gong, B. Ding, D.-R. Lee, and S.-J. Park, "Fiber mats of poly(vinyl alcohol)/silica composite via electrospinning," Materials Letters, vol. 57, no. 9-10, pp. 15791584, 2003.

[32] K. H. Hong, J. L. Park, I. N. Hwan Sul, J. H. Youk, and T. J. Kang, "Preparation of antimicrobial poly(vinyl alcohol) nanofibers containing silver nanoparticles," Journal of Polymer Science B, vol. 44, no. 17, pp. 2468-2474, 2006.

[33] N. Ristolainen, P. Heikkilä, A. Harlin, and J. Seppälä, "Poly (vinyl alcohol) and polyamide-66 nanocomposites prepared by electrospinning," Macromolecular Materials and Engineering, vol. 291, no. 2, pp. 114-122, 2006.

[34] J. H. Park, M. R. Karim, I. K. Kim et al., "Electrospinning fabrication and characterization of poly(vinyl alcohol)/ montmorillonite/silver hybrid nanofibers for antibacterial applications," Colloid and Polymer Science, vol. 288, no. 1, pp. 115-121, 2010.

[35] B. Duan, L. Wu, X. Li et al., "Degradation of electrospun PLGA-chitosan/PVA membranes and their cytocompatibility in vitro," Journal of Biomaterials Science, vol. 18, no. 1, pp. 95115, 2007.

[36] H. W. Lee, M. R. Karim, H. M. Ji et al., "Electrospinning fabrication and characterization of Poly(vinyl alcohol)/ montmorillonite nanofiber mats," Journal of Applied Polymer Science, vol. 113, no. 3, pp. 1860-1867, 2009.

[37] S. Krause, D. R. Paul, and S. Newman, Polymer-Polymer Compatibility, in Polymer Blends, Academic Press, New York, NY, USA, 1978.

[38] D. F. Varnell and M. M. Coleman, "FT i.r. studies of polymer blends: V. Further observations on polyester-poly(vinyl chloride) blends," Polymer, vol. 22, no. 10, pp. 1324-1328, 1981.

[39] D. F. Varnell, J. P. Runt, and M. M. Coleman, "FT i.r. and thermal analysis studies of blends of poly( $\varepsilon$-caprolactone) with homo- and copolymers of poly(vinylidene chloride)," Polymer, vol. 24, no. 1, pp. 37-42, 1983.

[40] E. M. Woo, J. W. Barlow, and D. R. Paul, "Phase behavior of blends of aliphatic polyesters with a vinylidene chloride/vinyl chloride copolymer," Journal of Applied Polymer Science, vol. 32, no. 3, pp. 3889-3897, 1986.

[41] M. S. Islam, N. Akter, and M. R. Karim, "Preparation of superhydrophobic membranes by electrospinning of fluorinated silane functionalized pullulan," Colloids and Surfaces A, vol. 362, no. 1-3, pp. 117-120, 2010.

[42] J. S. Lee, K. H. Choi, H. D. Ghim et al., "Role of molecular weight of atactic poly(vinyl alcohol) (PVA) in the structure and properties of PVA nanofabric prepared by electrospinning," Journal of Applied Polymer Science, vol. 93, no. 4, pp. 1638-1646, 2004.

[43] H. P. Seo, C. W. Son, C. H. Chung et al., "Production of high molecular weight pullulan by Aureobasidium pullulans HP2001 with soybean pomace as a nitrogen source," Bioresource Technology, vol. 95, no. 3, pp. 293-299, 2004.

[44] R. F. T. Stepto, Polymer Networks, John Wiley \& Sons, Chichester, UK, 1998.

[45] Y. M. Shin, M. M. Hohman, M. P. Brenner, and G. C. Rutledge, "Electrospinning: a whipping fluid jet generates submicron polymer fibers," Applied Physics Letters, vol. 78, no. 8, pp. 1149-1151, 2001. 



The Scientific World Journal

Submit your manuscripts at

http://www.hindawi.com

\section{World Journal}

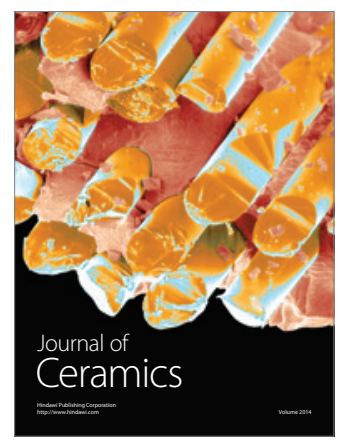

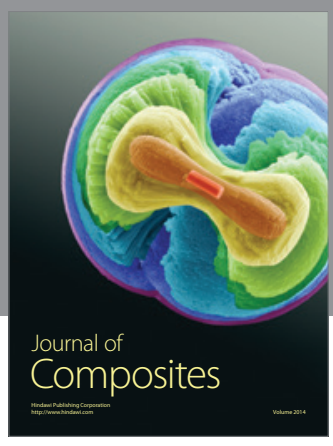
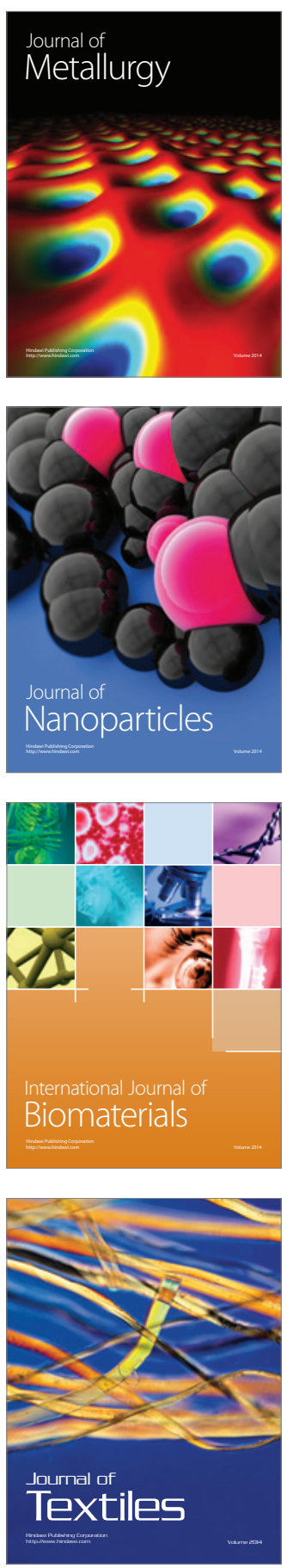